\title{
ISOLAMENTO E EFICIÊNCIA DE PLAQUEAMENTO DE PROTOPLASTOS DE CITROS ${ }^{1}$
}

\author{
MARIA ANGÉLICA PEREIRA DE CARVALHO COSTA²; FRANCISCO DE ASSIS ALVES \\ MOURÃO FILHO $^{3}$; BEATRIZ MADALENA JANUZZI MENDES ${ }^{4}$
}

\begin{abstract}
RESUMO - As recentes ferramentas biotecnológicas para o melhoramento in vitro de citros incluem a hibridação somática por fusão de protoplastos. A otimização dos protocolos de isolamento, plaqueamento e cultura de protoplastos, fundamental para maior eficiência na produção de híbridos somáticos, foi avaliada em 11 variedades cítricas. As soluções enzimáticas testadas foram: 1. celulase Onozuka RS, 1\%; macerase R-10, 1\%, pectoliase Y-23, 0,2\%; 2. celulase Onozuka R-10, 0,2 \%; macerase R-10, 0,3\%; driselase, 0,1\%; 3 . celulase Onozuka R-10, 1\%; macerase R-10, 0,2\%; driselase, 0,1\%. O plaqueamento dos protoplastos foi realizado em meio de cultura EME $0,7 \mathrm{M}$, nas densidades de $2 \times 10^{4} ; 5 \times 10^{4} ; 10^{5} ; 2 \times 10^{5}$ e $3 \times 10^{5}$ protoplastos. $\mathrm{mL}^{-1}$, no escuro, a $25 \pm 1^{\circ} \mathrm{C}$. A solução enzimática 1 possibilitou melhor rendimento no isolamento de protoplastos para a maioria das variedades, exceto para o limão- 'Cravo', onde o melhor rendimento foi obtido na solução enzimática 3, e para as laranjas-doces 'Valência' e 'Succari', que apresentaram maiores rendimentos na solução enzimática 2. A eficiência final de plaqueamento, avaliada aos 90 dias de cultivo, foi superior nas densidades de $10^{5}$ e $2 \times 10^{5}$ protoplastos. $\mathrm{mL}^{-1}$, para todas as variedades. O desenvolvimento de embriões somáticos foi observado em todas as variedades, exceto para tangor 'Murcote'.
\end{abstract}

Termos para indexação: Citrus, hibridação somática, melhoramento genético, protoplasto

\section{ISOLATION AND PLATTING EFFICIENCY OF CITRUS PROTOPLASTS}

\begin{abstract}
Recent biotechnological tools for citrus improvement include somatic hybridization by protoplast fusion. The optimization of protoplast isolation, platting and culture, essential for hybrid regeneration, was evaluated in 11 citrus varieties. The enzymatic solutions tested were: 1 . cellulase Onozuka RS, $1 \%$; macerozyme R-10, 1\%, pectoliase Y-23, 0.2\%; 2. celullase Onozuka R-10, $0.2 \%$; macerozyme R-10, $0.3 \%$; driselase, $0.1 \%$; 3. celulase Onozuka R-10, $1 \%$; macerase R-10, $0.2 \%$; driselase, $0.1 \%$. Protoplasts were cultured in EME $0.7 \mathrm{M}$ at densities of $2 \times 10^{4} ; 5 \times 10^{4} ; 10^{5} ; 2 \times 10^{5}$ e $3 \times 10^{5}$ protoplasts. $\mathrm{mL}^{-1}$, in darkness, at $25 \pm 1^{\circ} \mathrm{C}$. The enzymatic solution 1 resulted in better protoplast isolation for most of the varieties studied, except for Rangpur lime, which presented higher isolation efficiency on enzymatic solution 3, and for 'Valencia' and 'Succari' sweet oranges, with better results were obtained on enzymatic solution 3. Final platting efficiency, evaluated 90 days after culture, was higher at the densities of $10^{5}$ e $2 \times 10^{5}$ protoplasts.mL'-1, for all varieties. Somatic embryogenesis was observed for all varieties, except for 'Murcott' tangor.
\end{abstract}

Index terms: citrus, protoplast, somatic hybridization, variety improvement

\section{INTRODUÇÃO}

Programas de melhoramento de citros vêm sendo desenvolvidos desde o século passado (Davies \& Albrigo, 1994); entretanto, os métodos convencionais que utilizam a hibridação sexual, têm apresentado pouco sucesso (Vardi et al., 1982). Isto ocorre devido a aspectos da biologia reprodutiva dos citros, como alta heterozigose, esterilidade do grão de pólen e óvulo, incompatibilidade sexual, poliembrionia nucelar e juvenilidade (Vardi et al., 1975; Ling et al., 1989, Grosser \& Gmitter Junior, 1990a).

A partir da década de oitenta, com o avanço das técnicas de biotecnologia, a hibridação somática pela fusão de protoplastos também passou a ser utilizada em programas de melhoramento de citros, superando as barreiras genéticas impostas à hibridação sexual, possibilitando a obtenção de alotetraplóides, os quais combinam o genoma nuclear de ambos os parentais (Grosser \& Gmitter Junior, 1990a).

Para o estabelecimento de um programa de hibridação somática, é necessário desenvolver um protocolo de isolamento e cultivo de protoplastos in vitro, com regeneração de plantas. Protoplastos de citros têm sido obtidos de tecido foliar (Kobayashi et al., 1991; Saito et al., 1993) e de calos e células em suspensão (Oliveira,1993), sendo estes os responsáveis pela regeneração de plantas, utilizando-se de soluções enzimáticas constituídas de celulase e pectoliase (Carneiro et al., 1998), dissolvidas em metade das concentrações dos macronutrientes do meio MT (Murashige \& Tucker, 1969), sais minerais de CPW

1 (Trabalho 092/2001). Recebido: 30/04/2001. Aceito para publicação: 08/03/2002. Apoio financeiro: FAPESP, Fundecitrus.

2 Departamento de Fitotecnia da Escola de Agronomia da Universidade Federal da Bahia (AGR-UFBA), Pós-graduando em Fitotecnia, Escola Superior de Agricultura "Luiz de Queiroz", Universidade de São Paulo (USP/ESALQ). Bolsista CAPES/PICDT.

3 Departamento de Produção Vegetal, Escola Superior de Agricultura "Luiz de Queiroz", Universidade de São Paulo (USP/ESALQ). Caixa Postal 9, 13418-900, Piracicaba, SP. Bolsista CNPq. Autor correspondente. famourao@esalq.usp.br

4 Laboratório de Biotecnologia Vegetal, Centro de Energia Nuclear na Agricultura, Universidade de São Paulo (USP/CENA). Cx. Postal 97, 13416-970, Piracicaba, SP. Bolsista CNPq. 
(Frearson et al., 1973) ou em ácido 2- [N-morfolino]etanossulfônico (MES) e $\mathrm{NaH}_{2} \mathrm{PO}_{4}$ (Grosser \& Gmitter Junior, 1990b).

O primeiro isolamento de protoplastos de citros foi relatado por Vardi et al. (1975), utilizando a cv. 'Shamouti' de Citrus sinensis. Vários são os protocolos de isolamento de protoplastos de citros existentes na literatura, como os descritos por Vardi et al. (1987), Kobayashi et al. (1983) e Grosser \& Gmitter Júnior (1990a). Embora algumas generalizações para obtenção de protoplastos possam ser feitas, as condições necessárias para o isolamento podem variar de espécie para espécie e até mesmo de variedade para variedade.

No que se refere ao cultivo de protoplastos, a densidade de plaqueamento bem como a molaridade do meio de cultivo constituem-se os principais fatores da eficiência final de plaqueamento, definida como a porcentagem de protoplastos plaqueados que dividiram e formaram microcalos com 1-2 mm de diâmetro (Ochatt \& Power, 1992), com potencial de regeneração de plantas.

A eficiência de plaqueamento de protoplastos tem sido baixa, atingindo valores menores que $1 \%$ em algumas espécies (Banks \& Evans, 1976). Em trabalhos com protoplastos de citros, a eficiência de plaqueamento tem sido de 3,6 a 9,0\% (Vardi et al., 1975) e de 0 a 35\% (Grosser \& Gmitter Junior, 1990b), e cada espécie possui uma densidade mínima de plaqueamento abaixo da qual não ocorrem divisões celulares (Carneiro et al., 1998).

Desta forma, este trabalho teve como objetivo avaliar o efeito de três soluções enzimáticas no isolamento de protoplastos, bem como o efeito de diferentes densidades de cultivo na eficiência final de plaqueamento para 11 variedades cítricas.

\section{MATERIAL E MÉTODOS}

Cultivo de calos embriogênicos: Calos embriogênicos das laranjas-'Valência Rhode Red', 'Ruby Blood', 'Pêra' cv. 158, 'Natal', 'Valência' e 'Succari' (Citrus sinensis L. Osbeck); tangerinas'Cleópatra' (Citrus reshni Hort. ex Tanaka), 'Sunki' (Citrus sunki Hort. ex Tanaka); limão- 'Cravo' (Citrus limonia L. Osbeck) e 'Kinnow' (Citrus nobilis x Citrus deliciosa); e tangor-'Murcote' (Citrus reticulata $\mathrm{x}$ Citrus sinensis) obtidas do cultivo de tecido nucelar, mantidos em meio de cultura MT (Murashige \& Tucker, 1969), modificado pela adição de $500 \mathrm{mg} . \mathrm{L}^{-1}$ de extrato de malte, em ausência de luz, à temperatura de $27 \pm 1^{\circ} \mathrm{C}$, foram utilizados para isolamento de protoplastos. A cultura de calos embriogênicos apresentou idade de aproximadamente 3 anos, com subcultivos a cada 4 semanas.

Isolamento de protoplastos em função da solução enzimática: Foram utilizadas três soluções enzimáticas: 1 . Grosser \& Chandler (1987), composta de 1\% celulase Onozuka RS (Yakult), 1\% macerase R-10 (Yakult Honsha) e 0,2\% pectoliase Y-23 (Seishin); dissolvidas em solução de 0,7 M manitol, 24,5 mM CaCl${ }_{2} . \mathrm{H}_{2} \mathrm{O}$; $0,92 \mathrm{mM} \mathrm{NaH} \mathrm{PO}_{4}$ e $6,15 \mathrm{mM}$ de ácido 2-[N-morfolino]etanossulfônico (MES) (Grosser \& Gmitter Junior, 1990a), utilizando-se de $2 \mathrm{~mL}$ desta solução por $500 \mathrm{mg}$ de calo, diluído em 2 mL de meio de cultura BH3 0,7 M (Mourão Filho, 1995); 2. Kobayashi et al. (1983), constituída de 0,2 \% celulase Onozuka R-10, 0,3\% de macerozyme R-10 e 0,1\% driselase (Kyowa), dis- solvidas em solução com metade dos macroelementos do meio de cultura MT e 0,7 M de manitol, pH 5,7, utilizando-se de $5 \mathrm{~mL}$ desta solução por $500 \mathrm{mg}$ de calo, e 3. Ochatt et al. (1987), composta por: $1 \%$ celulase Onozuka R-10; 0,2\% macerase R-10 e 0,1\% driselase, dissolvidas em CPW 13 M (Freason et al., 1973) com 5 mM MES, pH 5,6, utilizando-se de $10 \mathrm{~mL}$ da solução por $500 \mathrm{mg}$ de calo. As soluções enzimáticas foram esterilizadas por meio de filtração $(0,22 \mathrm{~mm})$. A incubação foi realizada por um período de 10 horas, sob agitação orbital de $40 \mathrm{rpm}$, em ausência de luz, à temperatura de $27{ }^{\circ} \mathrm{C}$. Após digestão enzimática, os protoplastos foram purificados em gradiente de sacarose-manitol e diluídos em $5 \mathrm{~mL}$ do meio de cultura BH3 0,7 M. A avaliação dos resultados foi realizada com auxílio de hemocitômetro, determinando-se o rendimento de protoplastos por peso fresco de calo embriogênico utilizado. O delineamento experimental utilizado foi inteiramente casualizado em esquema fatorial $3 \times 3 \times 11$, sendo cada repetição constituída por uma placa de Petri com 500 mg de calo.

Densidades de plaqueamento no cultivo de protoplastos: Protoplastos purificados foram cultivados em cinco densidades $2 \times 10^{4} ; 5 \times 10^{4} ; 10^{5} ; 2 \times 10^{5} \mathrm{e} 3 \times 10^{5}$ protoplastos. $\mathrm{mL}^{-1}$, em meio de cultura EME 0,7 M em ausência de luz, a $25 \pm 1^{\circ} \mathrm{C}$ (Grosser \& Gmitter Júnior, 1990a). Aos 30 dias de cultivo, iniciou-se a redução da pressão osmótica, adicionando-se 10 a 12 gotas do meio de cultura 1:1:1 (v:v:v), 1 parte de BH3 0,6 M, 1 parte de EME 0,6 $\mathrm{M}$ e 1 parte de EME 0,146 M, transferindo-se a cultura para baixa iluminação. Em subcultivos posteriores (a cada 20 a 30 dias), quando a cultura de protoplastos já estava mais vigorosa, formando microcalos, adicionaram-se às microcolônias o meio de cultura 1:2 (v:v), o qual é composto por 1 parte do meio de cultura BH3 0,6 M e 2 partes de EME 0,146 M. Aos 90 dias de cultivo, foi avaliado o número de microcalos com 1-2 mm de diâmetro, transferindo-os para placa de Petri $(100 \times 15 \mathrm{~mm})$, contendo o meio de cultura semi-sólido EME suplementado com 25 g. $\mathrm{L}^{-1}$ de sacarose, a qual foi dividida em 8 campos, para facilitar a contagem das colônias. O delineamento experimental utilizado foi o inteiramente casualizado, com 3 repetições, sendo cada repetição constituída por uma placa de isolamento.

\section{RESULTADOS E DISCUSSÃO}

Verificou-se influência da variedade e da solução enzimática no isolamento de protoplastos (Tabela 1). Esses resultados já foram constatados por Mendes-da-Glória (1998), Oliveira et al. (1994) e Latado (1998). Estas diferenças estão relacionadas com características inerentes à parede celular, que, embora seus constituintes básicos sejam os mesmos, sua composição pode variar muito entre as espécies (Carneiro et al., 1998).

A comparação dos efeitos promovidos pelas três soluções enzimáticas permite concluir que a solução descrita por Grosser \& Chandler (1987) foi a mais eficiente no isolamento de protoplastos de calos, em que diversas variedades estudadas apresentaram bons resultados. O uso das soluções enzimáticas descritas por Ochatt et al. (1987) e Kobayashi et al. (1983) resultaram em suspensão de protoplastos com muitas impurezas e com baixo rendimento (número de protoplastos.g de calo ${ }^{-1}$ ), mesmo em variedades responsivas em trabalhos anteriores, tais como, as laranjas-'Natal', 'Ruby Blood' e 'Valência Rohde Red'. O rom- 
pimento da membrana plasmática permite a liberação de compostos fenólicos, que promovem a síntese anormal da parede celular, atraso nas divisões e até morte das células, prejudicando, portanto, o cultivo de protoplastos íntegros (Evans \& Bravo, 1983).

Quanto à densidade de plaqueamento, verificou-se a formação de um maior número de microcolônias nas densidades de $10^{5}$ e 2 × $10^{5}$ protoplastos. $\mathrm{mL}^{-1}$, o que pode ser constatado pela eficiência de plaqueamento, a qual variou de $6 \%$ (tangerina'Kinnow') a 8,5\% (tangerina-'Sunki') e de 7,2\% (tangor'Murcote') a 9,8\% (tangerina- 'Cleópatra'), respectivamente (Figura 1). Estes resultados se encontram dentro dos limites citados por Grosser \& Gmitter Junior (1990b), que variam de 0 a 35\%, e por Vardi et al. (1975), que encontraram variações de 3,6 a 9,0\%.

A eficiência de plaqueamento foi muito baixa nas densidades de plaqueamento de $2 \times 10^{4}$ e $5 \times 10^{4}$ protoplastos. $\mathrm{mL}^{-1}$ (Figura 1). Segundo Evans \& Bravo (1983), para cada espécie, existe uma densidade mínima de plaqueamento na qual não ocorre divisão celular. Por outro lado, o incremento na densidade para $3 \times 10^{5}$ protoplastos. $\mathrm{mL}^{-1}$ não mostrou comportamento linear. As pouquíssimas colônias desenvolvidas cessaram o crescimento e, conseqüentemente, morreram aos 90 dias após o início do cultivo. Resultados semelhantes foram obtidos por Vardi et al. (1975), trabalhando com protoplastos da laranja-'Shamouti', na densidade de $4 \times 10^{5}$ protoplatos. $\mathrm{mL}^{-1}$. Em altas densidades, fenômenos de absorção e excreção dos protoplastos podem modificar profundamente o meio de cultura (Carneiro et al., 1998), ocorrendo acúmulo de substâncias tóxicas em níveis letais (Shain, 1985).

Após 5 a 8 semanas de cultivo, ocorreu formação de embriões somáticos, espontaneamente, em algumas colônias desenvolvidas nas densidades de plaqueamento de $10^{5}$ e $2 \times 10^{5}$. A resposta embriogênica variou entre as variedades estudadas (Tabela 2). Os maiores números de embriões somáticos foram obtidos em laranjas-doces ('Ruby Blood', 'Rohde Red', 'Natal',
'Valência'). Não foi observada a ocorrência de embriogênese somática em tangor-'Murcote'. O efeito da cultivar na capacidade regenerativa foi relatado por outros autores (Mendes-da-Glória, 1998; Benedito et al., 2000; Tomaz et al., 2001). Possivelmente, estas diferentes respostas estão relacionadas com características inerentes à composição da parede celular que, embora contenha os mesmos constituíntes básicos, pode apresentar composição diferenciada (Carneiro et al., 1998).

A histodiferenciação dos embriões somáticos de laranja-doce ocorreu de maneira regular, tendo sido visualizados embriões somáticos em diferentes estádios de desenvolvimento (globular, torpedo e cotiledonar). Estas diferentes fases de desenvolvimento foram relatadas por Kunitake \& Mii (1995) em laranja- 'Valência', após transferência de embriões somáticos em estádio globular para meio enriquecido com giberelina, e por Perez et al. (1998) em várias cultivares de citros.

Quanto às variedades de tangerinas, apenas a tangerina- 'Cleópatra' apresentou desenvolvimento dos embriões somáticos passando pelos estádios acima mencionados. No entanto, alguns embriões anormais foram observados. Os embriões somáticos formados nas variedades 'Kinnow' e 'Sunki' permaneceram em estádio globular.

Os embriões somáticos desenvolvidos em calos de limão- ‘Cravo' encontraram-se em estádio globular e partes deles com estrutura multicotiledonar. Resultado semelhante foi relatado por Tomaz et al. (2001) ao estudarem a histodiferenciação de embriões de citros in vitro.

Estudos envolvendo a regeneração de plantas via embriogênese somática in vitro têm relacionado a baixa conversão em plantas com as anormalidades observadas nos embriões somáticos. Dentre as alterações dos embriões somáticos observadas por diversos autores, estas variam principalmente em relação à morfologia do meristema apical caulinar e dos cotilédones (Passos et al., 1999; Fernando, 1999).

TABELA 1 - Número de protoplastos. $\mathrm{g}^{-1}$ de calo, em 11 variedades cítricas conforme solução enzimática.

\begin{tabular}{|c|c|c|c|}
\hline \multirow[b]{2}{*}{ Variedades } & \multicolumn{3}{|c|}{ Soluções enzimáticas } \\
\hline & 1. Grosser \& Chandler (1987) & $\begin{array}{c}\text { 2. Kobayashi et al., } \\
(1983)\end{array}$ & $\begin{array}{c}\text { 3. Ochatt et al., } \\
(1987)\end{array}$ \\
\hline & \multicolumn{3}{|c|}{ Número de protoplastos. $\mathrm{g}^{-1}$ de calo } \\
\hline Tangerina-'Cleópatra' & $4.69 \times 10^{6} \mathrm{aA}$ & $2.08 \times 10^{6} \mathrm{aC}$ & $2.78 \times 10^{6} \mathrm{aB}$ \\
\hline Tangerina-'Kinnow' & $7.03 \times 10^{6} \mathrm{bA}$ & $1.81 \times 10^{6} \mathrm{aC}$ & $5.59 \times 10^{6} \mathrm{bB}$ \\
\hline Tangerina-'Sunki' & $10.88 \times 10^{6} \mathrm{cA}$ & $3.51 \times 10^{6} \mathrm{bC}$ & $5.16 \times 10^{6} \mathrm{bB}$ \\
\hline Laranja-'Ruby Blood' & $17.72 \times 10^{6} \mathrm{dA}$ & $4.88 \times 10^{6} \mathrm{cC}$ & $10.8 \times 10^{6} \mathrm{cB}$ \\
\hline Laranja-'V. Rohde Red' & $10.85 \times 10^{6} \mathrm{cA}$ & $2.86 \times 10^{6} \mathrm{aC}$ & $4.9 \times 10^{6} \mathrm{~dB}$ \\
\hline Laranja-'Pêra'cv. 158 & $7.06 \times 10^{6} \mathrm{bA}$ & $2.69 \times 10^{6} \mathrm{aC}$ & $4.8 \times 10^{6} \mathrm{~dB}$ \\
\hline Laranja-'Natal' & $14.83 \times 10^{6} \mathrm{eA}$ & $3.17 \times 10^{6} \mathrm{bC}$ & $4.9 \times 10^{6} \mathrm{~dB}$ \\
\hline Laranja-'Succari' & $4.99 \times 10^{6} \mathrm{aA}$ & $6.87 \times 10^{6} \mathrm{dC}$ & $1.65 \times 10^{6} \mathrm{eB}$ \\
\hline Laranja-'Valência'cv. 63 & $19.31 \times 10^{6} \mathrm{fA}$ & $22.95 \times 10^{6} \mathrm{eC}$ & $20.99 \times 10^{6} \mathrm{fB}$ \\
\hline Limão - 'Cravo' & $22.68 \times 10^{6} \mathrm{gA}$ & $19.24 \times 10^{6} \mathrm{fC}$ & $23.68 \times 10^{6} \mathrm{fB}$ \\
\hline Tangor-'M urcote' & $21.11 \times 10^{6} \mathrm{~g} \mathrm{~A}$ & $15.18 \times 10^{6} \mathrm{gC}$ & $19.0 \times 10^{6} \mathrm{fB}$ \\
\hline $\mathrm{C} \mathrm{V}$ & 0.940 & 0.940 & 0.940 \\
\hline
\end{tabular}

Médias com a mesma letra minúscula na coluna e maiúscula na linha não diferem entre si (Tukey 0,01$)$ 
TABELA 2 - Indução da embriogênese somática (número de embriões. placa de Petri ${ }^{-1}$ ) nas linhagens de calo de 11 variedades cítricas em função da densidade de plaqueamento (30 dias de cultivo).

\begin{tabular}{|c|c|c|c|c|}
\hline \multirow{3}{*}{ Variedades } & \multicolumn{4}{|c|}{ Densidades de plaqueamento } \\
\hline & $2 \times 10^{4}$ & $5 \times 10^{4}$ & $10^{5}$ & $2 \times 10^{5}$ \\
\hline & \multicolumn{4}{|c|}{ Número de embriões. placa de Petri ${ }^{-1}$} \\
\hline Tangerina-'Cleópatra' & 0 & 19 & 27 & 11 \\
\hline Tangerina-'Kinnow' & 0 & 11 & 19 & 8 \\
\hline Tangerina-'Sunki' & 0 & 10 & 24 & 6 \\
\hline Laranja-'Ruby Blood' & 0 & 32 & 45 & 15 \\
\hline Laranja-'Valência Rohde Red' & 0 & 30 & 48 & 18 \\
\hline Laranja-'Pêra'cv. 158 & 0 & 18 & 36 & 10 \\
\hline Laranja-'Natal' & 0 & 19 & 34 & 9 \\
\hline Laranja-'Succari' & 0 & 10 & 36 & 6 \\
\hline Laranja-'Valência'cv. 63 & 0 & 35 & 46 & 19 \\
\hline Limão-'Cravo' & 0 & 10 & 22 & 3 \\
\hline Tangor-'Murcote' & 0 & 0 & 0 & 0 \\
\hline
\end{tabular}

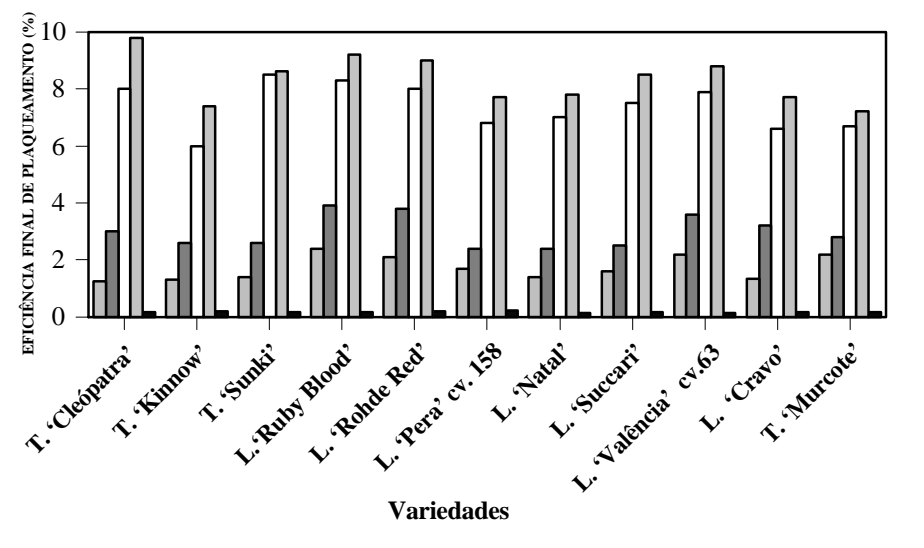

Densidade de plaqueamento Número de protoplastos. $\mathbf{m L}_{5}^{-1}$ $\square 2 \times 10^{4} \square 5 \times 10^{4} \square 1 \times 10^{5} \square 2 \times 10^{5} \square 3 \times 10^{5}$

FIGURA 1 - Eficiência de plaqueamento (\%), em função da densidade de cultivo (número de protoplastos. $\mathrm{mL}^{-1}$ ), em 11 variedades cítricas.

\section{CONCLUSÕES}

1. O rendimento de protoplastos é influenciando pela variedade e composição da solução enzimática.

2. A eficiência final de plaqueamento variou em função da densidade de cultivo dos protoplastos.

3. As melhores taxas de divisão celular e, conseqüentemente, formação de colônias ocorreram nas densidades de plaqueamento de $10^{5}$ e $2 \times 10^{5}$ protoplastos. $\mathrm{mL}^{-1}$.

4. A intensidade da embriogênese somática foi dependente da variedade estudada, variando em função da densidade de plaqueamento.

\section{REFERÊNCIAS BIBLIOGRÁFICAS}

BANKS, M. S.; EVANS, P. K. A comparison of the isolation and culture of mesophyll protoplasts from several Nicotiana species and theirs hybrids. Plant Science Letters, Amsterdan, v.7, p. 409-416, 1976.

BENEDITO, V.A.; MOURÃO FILHO, F.A.A.; MENDES, B.M.J. Calogênese, embriogênese somática e isolamento de protoplastos de laranja-doce. Scientia Agricola, Piracicaba, v.57, n.1, p.33-38, 2000.

CARNEIRO, V.T. de C.; CONROI, T.; BARROS, L.M.G.; MATSUMOTO, K. Protoplastos: cultura e aplicações. In: TORRES, A.C.; CALDAS, L.S.; BUSO, J.A. (Ed.) Cultura de tecidos e transformação genética de plantas. Brasília: EMBRAPA, SPI, CNPH, 1998. v.1, p.413-458.

DAVIES, F.; ALBRIGO, L. Citrus. Wallingford: CAB International, 1994. cap.2, p.12-51.

EVANS, D.A.; BRAVO, J.E. Protoplast isolation and culture. In: EVANS, D.A.; SHARP, W.R.; AMMIRATO, P.V.; YAMADA, Y. (Ed.) Handbook of plant cell culture. New York: McMillan Press, 1983. v.1, p.124-176.

FERNANDO, J.A. Estudos anatômicos da embriogênese somática in vitro em soja (Glycine Max (L.) Merrill). 86f. Dissertação (Mestrado) - Escola Superior de Agricultura "Luiz de Queiroz”, Universidade de São Paulo, Piracicaba, 1999.

FREARSON, E.M.; POWE, J.B.; COCKING, E.C. The isolation, culture and regeneration of Petunia leaf protoplasts. Developmental Biology, Orlando, v.33, p.130-137, 1973. 
GROSSER, J.W.; GMITTER JUNIOR, F.G. Somatic hybridization of Citrus with wild relatives for germplasm enhancement and cultivar development. HortScience, Alexandria, v.25, n.2, p.147151, 1990a.

GROSSER, J.W.; GMITTER JUNIOR, F.G. Protoplast fusion and citrus improvement. Plant Breeding Reviews, New York, v.8, p.339-374, 1990b.

GROSSER, J.W.; CHANDLER, J.L. Aseptic isolation of leaf protoplasts from Citrus, Poncirus, Citrus x Poncirus Hybrids and Severinia for use in somatic hybridization experiments. Scientia Horticulturae, Amsterdam, v.31, p.253-257, 1987.

KOBAYASHI, S.; OIYAMA, I.; YOSHINAGA, K.; OHGAWARA, T.; ISHII, S. Fertility in an intergeneric somatic hybrid plant of Rutaceae. HortScience, Alexandria, v.26, p.207-210, 1991.

KOBAYASHI, S.; UCHIMYA, H.; IKEDA, I. Plant regeneration from 'Trovita' orange protoplasts. Japanese Journal of Breeding, Bunkyo-Ku, v.33, p.119-122, 1983.

KUNITAKE, H.; MII, M. Somatic embryogenesis in Citrus species. In: BAJAJ, Y.P.S. (Ed.) Somatic embryogenesis and synthetic seed I. Berlin: Springer-Verlag, 1995. p.280-298. (Biotechnology in Agriculture and Forestry, 30).

LATADO, R.R. Hibridação somática entre limão-Cravo (Citrus limonia Osbeck) e tangerina-Cleópatra (Citrus reshni Hort.). 146f. Tese (Doutorado) - Escola Superior de Agricultura "Luiz de Queiroz”, Universidade de São Paulo, Piracicaba, 1998.

LING, J.-T.; NITO, N.; IWAMASA, M. Plant regeneration from protoplasts of Calamondin (Citrus madurensis Lour.). Scientia Horticulturae, Amsterdam, v.39, p.325-333, 1989.

MENDES-DA-GLÓRIA, F.J. Hibridação somática entre laranja-'Caipira' e limão-'Cravo' através de fusão de protoplastos. 78f. Dissertação (Mestrado) - Escola Superior de Agricultura “Luiz de Queiroz”, Universidade de São Paulo, Piracicaba, 1998.

MOURÃO FILHO, F.A.A. Protoplast fusion of citrus for rootstock and scion improvement with emphasis on wide hybridization. 152f. Tese (Ph.D) - University of Florida, Gainesville, 1995.

MURASHIGE, T.; TUCKER, D.P.H. Growth factor requirements of citrus tissue culture. In: CITRUS SYMPOSIUM, 1., 1969, Riverside. Proceedings... Riverside: University of California, 1969. p.1155-1161.

OCHATT, S.J.; POWER, J.B. Plant regeneration from cultured protoplasts of higher plants. In: FOWLER, M.W.; WARREN, G.S.; MOO-YOUNG, M. (Ed.) Plant Biotechnology: comprehen- sive biotechnology. Oxford: Pergamon Press, 1992. p.99-127.

OCHATT, S.J.; COCKING, E.C.; POWER, J.B. Isolation, culture and plant regeneration of colt cherry (Prunus avium $\mathrm{x}$ pseudocerasus) protoplasts. Plant Science, Sofia, v.50, p.139$143,1987$.

OLIVEIRA, R.P. Cultura de calos, células em suspensão e protoplastos de porta-enxertos de citros. $117 \mathrm{f}$. Dissertação (Mestrado) - Centro de Energia Nuclear na Agricultura, Universidade de São Paulo, Piracicaba, 1993.

OLIVEIRA, R.P.; MENDES, B.M.J.; TULMANN NETO, A. Obtenção e cultura de calos nucelares de limão-Cravo, tangerinaCleópatra e Poncirus trifoliata. Revista Brasileira de Fisiologia Vegetal, Brasília, v.6, p.115-119, 1994.

PASSOS, I.; APPEZZATO-DA-GLÓRIA, B.; VIEIRA, M.L.C. Embryogenic responses of Vitis spp.: effects of genotype and polyvinylpyrolidone. Vitis, Siebeldingen, v.38, p.47-50, 1999.

PEREZ, R.M.; GALIANA, A.M.; NAVARRO, L.; DURAN-VILA, N. Embryogenesis in vitro of several Citrus species and cultivars. Journal of Horticultural Science \& Biotechnology, v.73, n.6, p.796-802, 1998.

SAITO, W.; OHGAWARA, T.; SHIMIZU, J.; ISHII, S.; KOBAYASHI, S. Citrus cybrid regeneration following cell fusion between nucellar cells and mesophyll cells. Plant Science, Sofia, v.88, p.195-201, 1993.

SHAIN, E.A. Totypotency of tomato protoplasts. Theoretical and Applied Genetics, Berlim, v.69, p.235-240, 1985.

TOMAZ, M.L.; MENDES, B.M.J.; MOURÃO FILHO, F.A.A.; DEMÉTRIO, C.B.; JANSAKUL, N.; RODRIGUEZ, A.P.M. Somatic embryogenesis in Citrus spp: carbohydrate stimulation and histodifferentiation. In Vitro Cellular \& Developmental Biology, Columbia, v.37, n.4, p.446-452, 2001.

VARDI, A.; SPIEGEL-ROY, P.; GALUN, E. Citrus cell culture: isolation of protoplasts, plating densities, effect of mutagens and regeneration of embryos. Plant Science Letters. Limerick, v.4, p.31-36, 1975.

VARDI, A.; SPIEGEL-ROY, P.; GALUN, E. Plant regeneration from Citrus protoplasts: variability in methodological requirements among cultivars and species. Theoretical and Applied Genetics, Berlin, v.62, p.171-176, 1982.

VARDI, A.; BREIMAN, A.; GALUN, E. Citrus cybrids: production by donor-recipient protoplast-fusion and verification by mitochondrial-DNA restriction profiles. Theoretical and Applied Genetics, Berlin, v.75, p.51-58, 1987. 